\title{
Experimental and Numerical Investigation of the Thermal Transition Area at the Heated Bottom- Wall of a Horizontal Rectangular Channel
}

\author{
Jaroslav Pulec ${ }^{1, *}$, Jan Novosád ${ }^{1}$, Václav Vinš ${ }^{2}$, and Petra Dančová ${ }^{1}$ \\ ${ }^{1}$ Technical University of Liberec, Department of Power Engineering Equipment, Studentská 2, 46001 \\ Liberec, Czech Republic \\ ${ }^{2}$ Institute of Thermomechanics of the Czech Academy of Sciences, Dolejškova 5, 18200 Prague 8, \\ Czech Republic
}

\begin{abstract}
This article represents a part of an ongoing work on the preparation of an experimental rectangular channel for the PIV and LIF measurements of vortex structures and temperature field in a nonisothermal water flow. The main aim of the current study is to develop a sufficiently accurate simplified numerical model of the real problem. The basic requirements for thermal properties of heated bottom-wall are specified. In the computational model, there are several simplifications such as 2D case and a constant temperature of a heated surface along the longitudinal coordinate. Results of the numerical simulation of the fluid flow and heat transfer are verified on the experimental data obtained in a laboratory channel with the same geometry and similar flow conditions. The presented results helped to define additional requirements on the design of a new experimental channel intended for investigation of the flow instabilities in a non-isothermal liquid flow.
\end{abstract}

\section{Introduction}

The thermal stability and the formation of a secondary water flow in rectangular horizontal channels with heated walls has been investigated experimentally for several decades. This problem represents a basic case for the investigation of instabilities in a nonisothermal flow. However, most of the studies presented so far do not provide sufficient information about the actual design of the heated segment and its thermal characteristics. For the accurate investigation of thermal stability, a steep onset of heating on a smooth channel wall is required. A preheating caused by secondary heat conduction in the flow direction can adversely affect the flow regime in the channel.

Several studies focused on the flow in a channel with the heat wall have been introduced since 1980's. Osborne and Incropera [1] carried out a study on an effect of top and bottom wall heating in a horizontal rectangular channel. Similarly, Incropera et al. [2] and Maughan and Incropera [3] published articles dealing with the longitudinal rolls caused by mixed convection in channels with heated bottom. Recently, Benderradji et al. [4] and

\footnotetext{
Corresponding author: jaroslav.pulec@,tul.cz
} 
Koffi et al. [5]. Mey et al. [6] presented interesting results obtained with a modern planar PIV measurement system. Luijkx et al. [7] investigated transversal vortex structures in a water flow channel. Several measuring or visualizations was performed in an air flow channel. Mergui et al. [8] studied the influence of sidewalls positioning on the longitudinal rolls, their number and spacing. Hwang et al. [9] carried out an experiments with varying channel height.

Technical solutions of various channels employed by these researchers have been recently summarized by Pulec et al. [10]. The authors defined general requirements for the construction of a new channel convenient for the investigation of thermal flow instabilities.

As already mentioned, the special requirement for the heating part of the channel bottom-wall is to realize it such a way that the thermally influenced area in front of the heated segment is eliminated. Due to the heat transfer from the channel wall to the flowing water, the heat transfer coefficient is gradually changing along the longitudinal coordinate as the thermal boundary layer thickness changes. Following empirical correlation for the Nusselt number describes the conditions of laminar forced convection in the area near the onset point of heating where the secondary flow is not detectable yet [1].

$$
\mathrm{Nu}_{\mathrm{H}}=\left[1.656 \mathrm{Gz}_{\mathrm{H}}+0.012 \mathrm{Ra}_{\mathrm{H}, \mathrm{q}} \frac{3}{4}\right]^{\frac{1}{3}}
$$

In equation (1), $\mathrm{Gz}_{\mathrm{H}}=H \mathrm{Re}_{\mathrm{H}} \operatorname{Pr} / x$ stands for the Graetz number and $\mathrm{Ra}_{\mathrm{H}, \mathrm{q}}=$ $g \beta H^{4} q / k v \alpha$ is the modified Rayleigh number defined by the uniform heat flux density $q\left(\mathrm{~W} \cdot \mathrm{m}^{-2}\right)$ of a heater related to the channel height $H(\mathrm{~m})$. Other quantities are defined in the nomenclature. The term with Gz describes the forced convection part and the term with $\mathrm{Ra}$ the natural convection part. It is worth noting that the Nusselt number along the heated bottom generally increases with the flow rate and the heat flux density and decreases with longitudinal coordinate $x$. Figure 1 shows dependence of the Nusselt number on the longitudinal coordinate for various values of the heat flux density $q$ and the Reynolds number Re given as a function of average flow velocity $u\left(\mathrm{~m} \cdot \mathrm{s}^{-1}\right)$. As can be seen, the increasing Reynolds number causes larger increase of the Nusselt number than the rising heat flux density especially in the region close to the onset of heating at $x=0$.

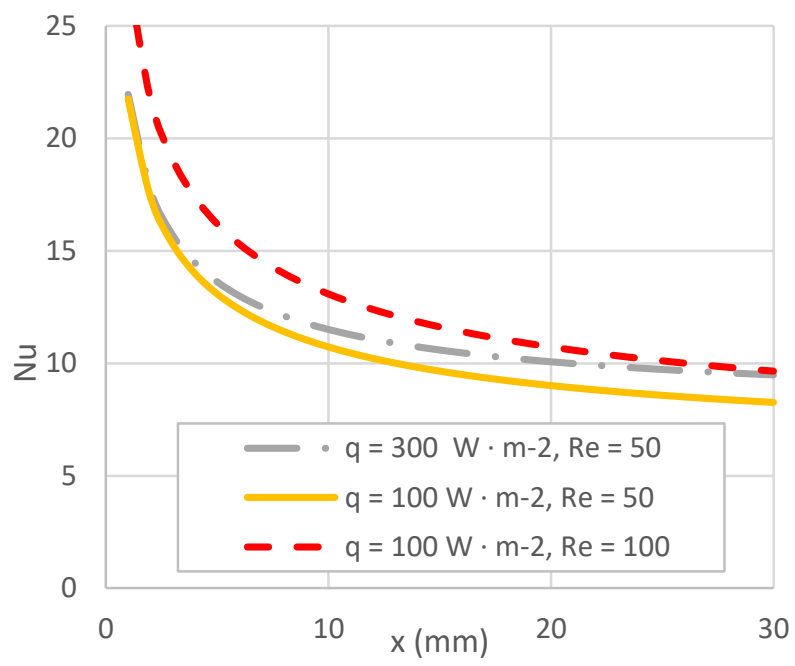

Fig. 1. Dependence of the Nusselt number on the longitudinal coordinate for different flow parameters at the temperature of $25^{\circ} \mathrm{C}$. The onset of heating occurs at $x=0$. 
In Figure 2, comparison of the experimental data by Maughan and Incropera [11] with eq. 1 is plotted. The experiments are in relatively good agreement with the correlation.

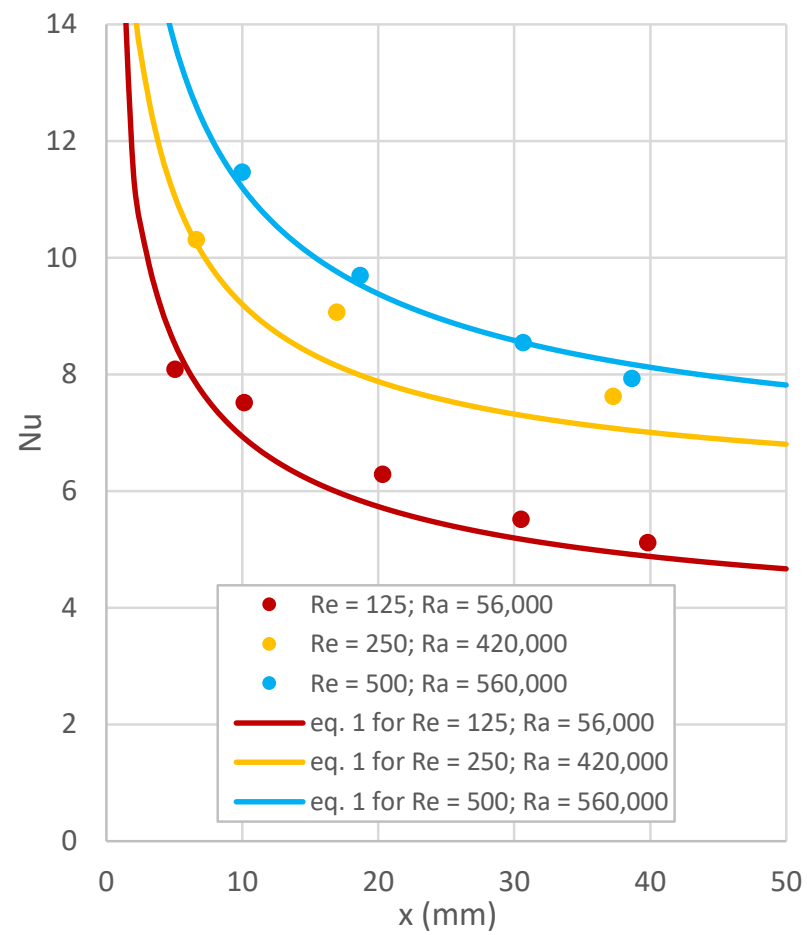

Fig. 2. Correlation of the experimental data by Maughan and Incropera [11] with eq. $1 ; \operatorname{Pr}=0.7$.

Given problem of the thermal convection can be described by the Newton's law of cooling [12], when the equality of heat fluxes at the interface between the solid wall and the fluid is considered:

$$
q_{\mathrm{h}}=h\left(T_{\mathrm{w}}-T_{\mathrm{in}}\right),
$$

where $h\left(\mathrm{~W} \cdot \mathrm{m}^{-2} \cdot \mathrm{K}^{-1}\right)$ is the heat transfer coefficient, $T_{\mathrm{w}}$ and $T_{\text {in }}\left({ }^{\circ} \mathrm{C}\right)$ are the wall temperature and the inlet temperature, respectively. On the side of wall, the Fourier's law of conduction applies [12]:

$$
q_{\mathrm{k}}=-k \frac{T_{\mathrm{w}}-T_{\mathrm{f}}}{d_{1}}
$$

where $k\left(\mathrm{~W} \cdot \mathrm{m}^{-1} \cdot \mathrm{K}^{-1}\right)$ is thermal conductivity, $T_{\mathrm{f}}$ is temperature on the side of heat source, and $d$ (m) is the thickness of solid material. From the equality of equations (2) and (3), the Nusselt number can be derived in the following manner [12]:

$$
\mathrm{Nu}_{\mathrm{H}}=\frac{h H}{k} .
$$

In equation (4), $H$ marks the characteristic length, i.e. the channel height in our case.

Main aim of this work is to develop a suitable CFD model tailored to the existing experimental glass channel installed in our laboratory. The model predictions shall help 
to prepare an improved design of the new channel with a well-defined thermal transition area without an unfavourable secondary thermal conduction along the main flow coordinate.

\section{Methods}

The presented CFD simulation shall help to obtain valuable information about the thermal characteristics of the section where the heater begins to heat the bottom-wall. An important requirement for the design of the new experiment is that the longitudinal temperature profile, eventually the heat flux, rises along the flow axis as steep as possible. Moreover, the secondary heat conduction in the channel wall in the upstream direction shall be avoided.

Figure 3 indicates the physical nature of the problem. Behind position $x=0$ a thermal source supplies a uniform heat flux density $q$ to the bottom wall of a rectangular channel. A water flows with a given velocity profile as a function of coordinates $x, y$. In future work, material properties and thicknesses $d_{1}$ and $d_{2}$ will be modified to eliminate thermal influenced area in section $x<0$.

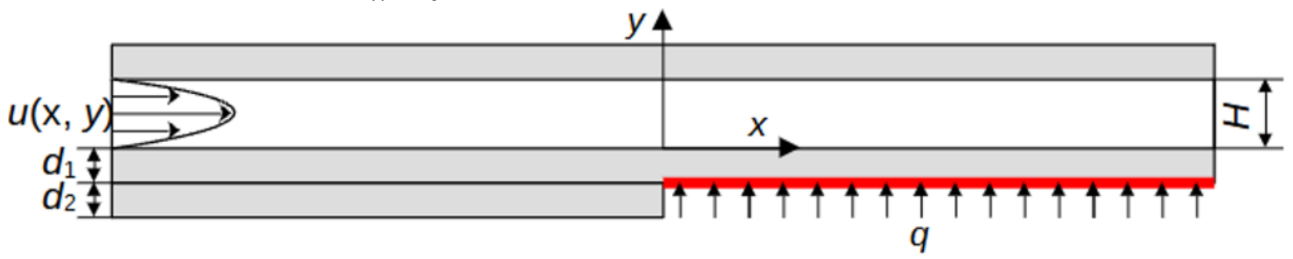

Fig. 3. Schematic description of the problem.

\subsection{Experimental setup}

Preliminary temperature measurements near the transition area were carried out in a test channel made of glass with the same cross-section of $200 \times 20 \mathrm{~mm}^{2}$ (width $\times$ height) as the designed new channel. Scheme of the test channel is depicted in Figure 4. Width of the inflow and outflow tanks is $400 \mathrm{~mm}$. Water flows from left to right using a pump and hosepipes, the flowrate is measured by a flow meter and regulated by valves with a secondary circuit.

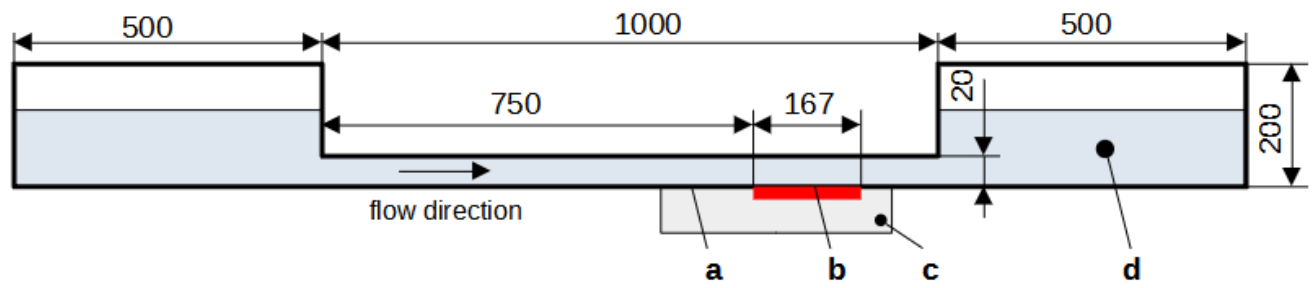

Fig. 4. Scheme of experimental channel. $a$ channel wall, $b$ foil heater, $c$ thermal insulation, $d$ water.

At the bottom wall, K-type thermocouples were placed along longitudinal coordinate approximately in a middle of the channel width. Scheme of thermocouples spacing is shown in Figure 5. Thermocouples are placed inside the channel directly on the glass wall $(y=0)$ in $x$-positions $(-40 ;-30 ;-20 ;-10 ; 0 ; 10 ; 20) \mathrm{mm}$ where " 0 " is the heating onset point. There are also two thermocouples at the outer side $(y=-10 \mathrm{~mm})$ in $x$-positions $(10$; 20) $\mathrm{mm}$ to determine the heat flux through the glass wall during the main measurement. The thermocouples are connected to the data acquisition unit with the recording time step 
of $0.1 \mathrm{~s}$. Temperature is determined as a time average of approximately $60 \mathrm{~s}$ interval. On the outer side of the test section, $50 \mathrm{~mm}$ thick thermal insulation was installed. According to the thermal resistances of the glass and the insulation, it is estimated that $99.2 \%$ of heat goes into the glass wall. The heat flux is produced by a resistive heating foil with the dimensions of $180 \times 168 \mathrm{~mm}^{2}$ (width $\times$ length) and thickness less than $1 \mathrm{~mm}$. The heating foil is connected to a laboratory DC power supply with adjustable current and voltage. An efficiency of heating foil is presumed to be $98 \%$. With regard to the length of the flow stabilizing section of around $750 \mathrm{~mm}$ and the volumetric flow rate of $\dot{V}=0.6 \mathrm{dm}^{3} \mathrm{~min}^{-1}$ the fully developed parabolic laminar velocity profile is expected in the test section area.

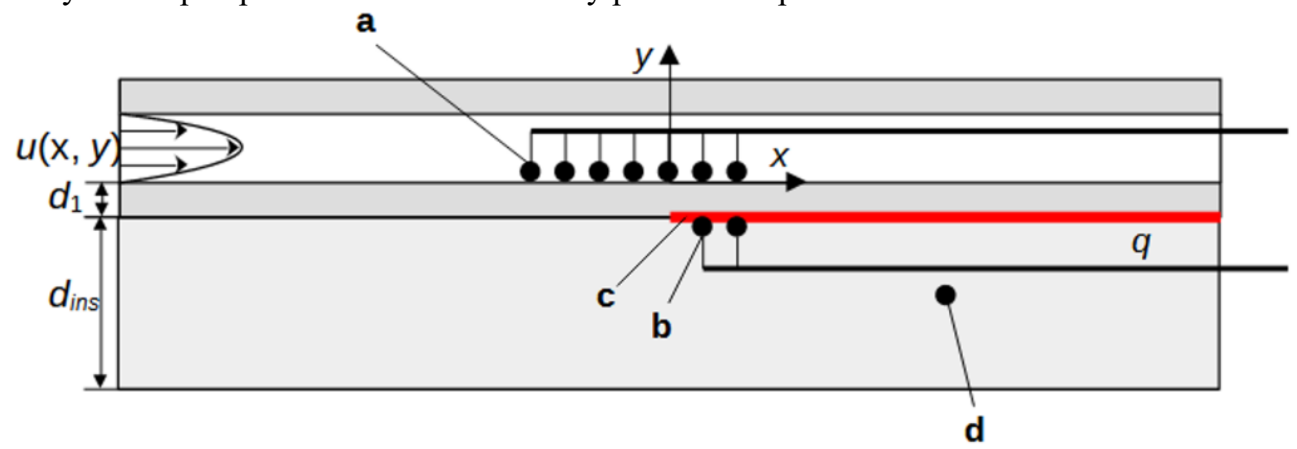

Fig. 5. Scheme of measuring space. $a$ inner thermocouples, $b$ outer thermocouples, $c$ foil heater, $d$ thermal insulation.

\subsection{Numerical simulation}

The numerical simulation intended for the design of a new experimental channel shall help to understand and accurately define the conductive and convective heat transfer inside the channel. The CFD model will be verified on the experimentally obtained temperatures measured in a testing glass channel. The validated model will be then used for the analysis of the new channel design.

The computational model represents the part of the channel near the $x=0$ position (see Figure 6). The total length is limited to $L=300 \mathrm{~mm}$. The length before the foil and the foil length are $L_{1}=100 \mathrm{~mm}, L_{\mathrm{f}}=167 \mathrm{~mm}$. The wall thickness $d_{1}$ and the height of the channel $H$ are the same as for the real channel.

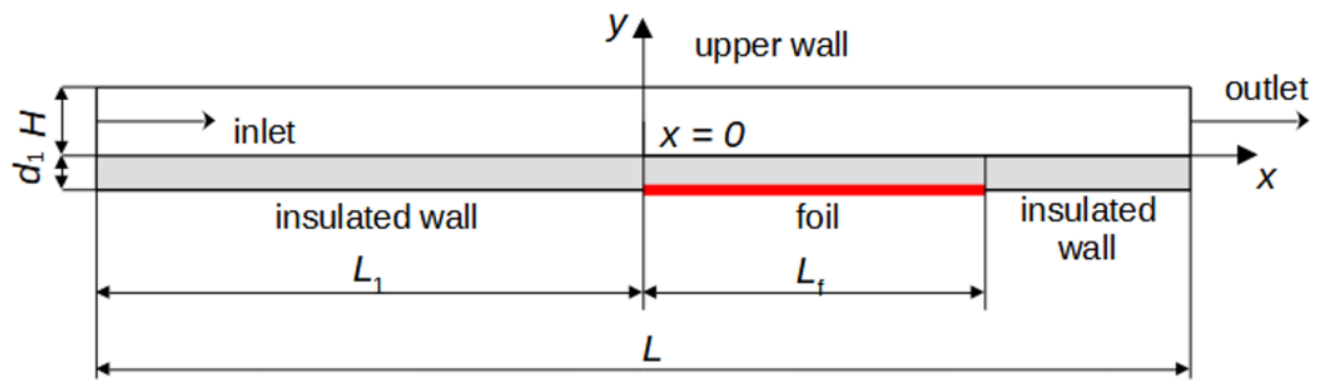

Fig. 6. Computational model - scheme.

Following the sketch in Figure 6 the 2D CAD model was designed. Then the computational grid was created using the ANSYS Meshing software. The grid consists of the solid and fluid domains. The discretization by quad elements was applied with the refinement in the area near the wall. The sizing of the face area was set to $1 \mathrm{~mm}$ with the 
refinement near the heat transfer surface in fluid region and $1 \mathrm{~mm}$ in solid region. The final grid, illustrated in Figure 7, has 14.000 elements in both fluid and solid.

Fig. 7. Computational grid.

ANSYS Fluent software was used as the CFD solver. The computation was considered as the steady state incompressible flow including the heat transfer in solid and fluid. The water as the working fluid is considered as incompressible liquid with constant thermophysical properties: $\rho=997.1 \mathrm{~kg} \cdot \mathrm{m}^{-3}, c_{\mathrm{p}}=4178.4 \mathrm{~J} \cdot \mathrm{kg}^{-1} \cdot \mathrm{K}^{-1}, k=0.606 \mathrm{~W} \cdot \mathrm{m}^{-1} \cdot \mathrm{K}^{-1}$ and $\eta=8.806 \cdot 10^{4} \mathrm{~Pa} \cdot \mathrm{s}$. The solid wall is made of glass with constant properties: $\rho=2600 \mathrm{~kg} \cdot \mathrm{m}^{-3}, c_{\mathrm{p}}=840 \mathrm{~J} \cdot \mathrm{kg}^{-1} \cdot \mathrm{K}^{-1}, k_{\mathrm{w}}=0.76 \mathrm{~W} \cdot \mathrm{m}^{1} \cdot \mathrm{K}^{-1}$.

The boundary conditions on the surfaces labelled in Fig. 6 were specified to match the experiment. Boundary types and parameters are listed in Table 1. The inlet temperature $T_{\text {in }}$ agrees with the surrounding temperature in the laboratory. The foil is defined by the surface temperature obtained from the experiments for two different foil power, minimum and nominal.

Table 1. Boundary conditions.

\begin{tabular}{|c|c|c|}
\hline label & type & parameters \\
\hline inlet & mass flow inlet & $\begin{array}{c}\dot{m}=0.01 \mathrm{~kg} \cdot \mathrm{s}^{-1} \\
T_{\mathrm{in}}=\{21.6 ; 22.1\}^{\circ} \mathrm{C}\end{array}$ \\
\hline outlet & pressure outlet & $p=0 \mathrm{~Pa}$ \\
\hline foil & wall (heated) & $T=T_{\mathrm{f}}=\{23 ; 27\}^{\circ} \mathrm{C}$ \\
\hline insulated wall & wall (adiabatic) & $q=0 \mathrm{~W} \cdot \mathrm{m}^{-2}$ \\
\hline upper wall & wall (adiabatic) & $q=0 \mathrm{~W} \cdot \mathrm{m}^{-2}$ \\
\hline
\end{tabular}

The second phase of the computations was made for the comparison with the results from other studies. The computational model was created with the same dimensions as given in Figure 6 but the walls were not taken into account. The heated part, i.e. the inner part of the channel wall parallel and corresponding to the foil, was defined by the specified heat flux at $q=300 \mathrm{~W} \cdot \mathrm{m}^{-2}$. The other boundaries are defined in the same way as described in Table 1.

The coupled solver has been used for computations. Energy equation have been applied to solve the heat transfer. The viscosity effects were solved by the laminar model. The PRESTO scheme for pressure and Second Order Upwind scheme for momentum and energy were applied. Totally 200 iterations were defined to reach the convergence, i.e. the stabilization of flow and temperature at the outlet.

The temperature profile on the heat transfer surface was finally evaluated. The results represent the temperature profile as a function of temperature $T(x)$. 


\section{Results and discussions}

\subsection{Heat flux density measurement}

For checking the heat conduction properties, a temperature characteristic as a dependence of heat flux density was measured and calculated. The heat flux density is determined using eq. (3) from the temperature measurement on both sides of the bottom wall as an average of values in $x$-positions of $10 \mathrm{~mm}$ and $20 \mathrm{~mm}$ for each heat power. The measured and calculated values are given in Table 2. As expected, the trend is relatively linear. The measured heat flux density corresponds to the assumed values in order of units or tenths (higher power) up to tens of percent (lower power).

Table 2. Measured and calculated data.

\begin{tabular}{|c|c|c|}
\hline dataset & $\boldsymbol{q}\left(\mathbf{W} \cdot \mathbf{m}^{-\mathbf{2}}\right)$ & $\boldsymbol{T}_{\text {f,ave }}\left({ }^{\circ} \mathbf{C}\right)$ \\
\hline MP1 & 86.342 & 23.023 \\
\hline MP2 & 130.255 & 23.815 \\
\hline MP3 & 195.139 & 24.929 \\
\hline MP4 & 306.488 & 26.765 \\
\hline MP4_2 & 323.240 & 27.099 \\
\hline MP5 & 440.318 & 28.775 \\
\hline MP6 & 750.615 & 33.427 \\
\hline
\end{tabular}

\subsection{Numerical simulation and experimental measurement comparison}

To compare the dependences of temperature on $x$-coordinate, the dataset MP1 and MP4 from Table 2 were chosen. Value of heat flux density of dataset MP4 is an expected maximum power of the future experiment. Figure 8 shows measured and computed bottom wall temperature inside the channel at the wall-water borderline as a function of longitudinal $x$-coordinate. The bottom curve shows longitudinal temperature profile for dataset MP1, the upper curve shows MP4 dataset. Note that inlet temperatures $T_{\text {in }}$ (dashed line) are different due to the continual heating of the circulating water during the measurement but the temperature was recorded for a sufficiently short time (around $60 \mathrm{~s}$ ) to say that the inlet temperature was constant. Solid circles in Fig. 8 denote measured temperatures in various $x$-positions. Temperature drop in the interval $x=(10 \div 20) \mathrm{mm}$ can be caused either by phenomenon of thermal stability loss where the temperature boundary layer is steeply increased due to secondary flow, thereby increasing cooling of the bottom wall or by flow disturbance from the thermocouples representing flow obstacles. Slight temperature deviation for MP4 dataset can be seen at a position of $x=-20 \mathrm{~mm}$. It should be noted that this deviation occurs only for this dataset and it can be caused by immediate deviation during temperature recording as an unspecified backflow or uncertainty of the measured temperature. 


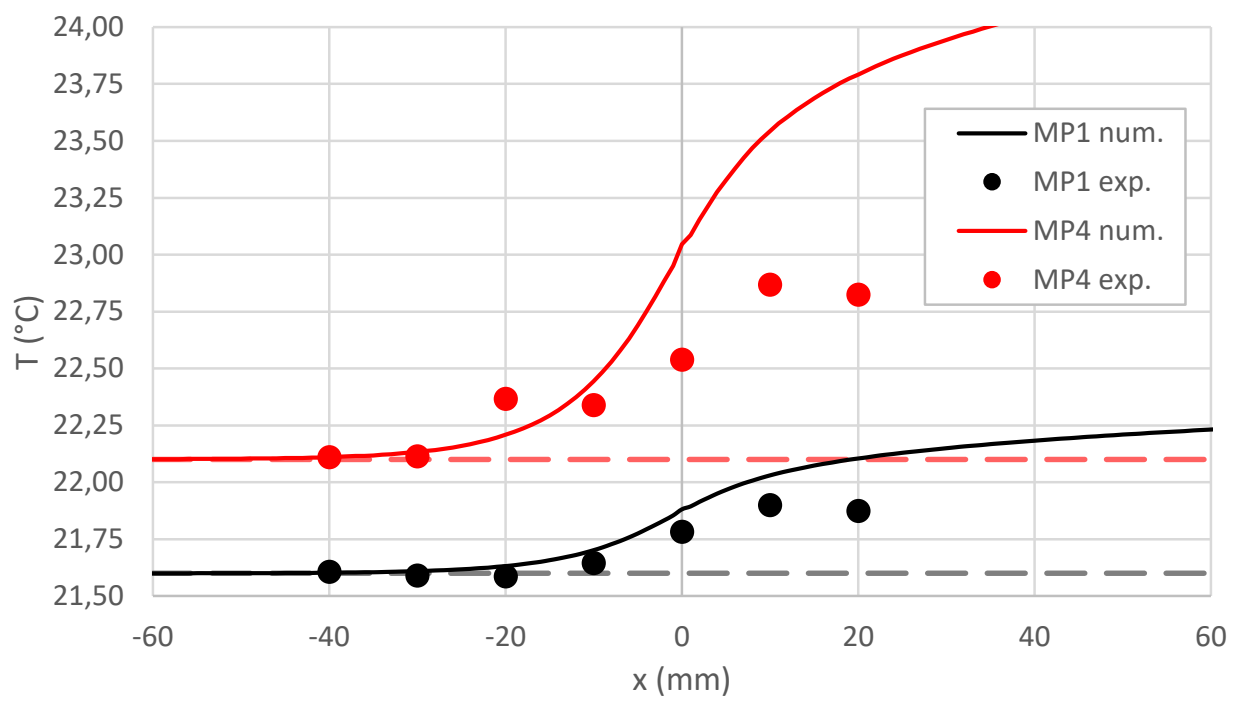

Fig. 8. Measured and numerical data comparison for MP1 and MP4 datasets.

The measured and numerical data deviations in thermocouple positions are listed in Table 3. Absolute deviation $\Delta T$ is determined as $\Delta T=T_{\text {exp }}-T_{\text {num }}$ and relative deviation $\delta T=\Delta T / T_{\text {in }}$.

Table 3. Numerical and experimental data deviation.

\begin{tabular}{|c|c|c|c|c|}
\cline { 2 - 5 } \multicolumn{1}{c|}{} & \multicolumn{2}{c|}{$\Delta \boldsymbol{T}\left({ }^{\circ} \mathbf{C}\right)$} & \multicolumn{2}{c|}{$\delta \boldsymbol{T}(\mathbf{\%})$} \\
\hline $\mathbf{x ~ ( m m )}$ & MP1 & MP4 & MP1 & MP4 \\
\hline-40 & 0.0030 & -0.0004 & 0.014 & -0.002 \\
\hline-30 & -0.0192 & -0.0202 & -0.089 & -0.091 \\
\hline-20 & -0.0456 & 0.1583 & -0.211 & 0.716 \\
\hline-10 & -0.0574 & -0.1042 & -0.266 & -0.471 \\
\hline 0 & -0.0979 & -0.5063 & -0.453 & -2.291 \\
\hline 10 & -0.1298 & -0.6750 & -0.601 & -3.054 \\
\hline 20 & -0.2303 & -0.9677 & -1.066 & -4.379 \\
\hline
\end{tabular}

From Figure 8 and Table 3, it can be seen that the numerical simulation generally overestimates the experimental values. For the practical use, when the preheating area shall be eliminated, it is more advantageous behaviour than if the trends were other way round. For a quick comparison, one convection case was also calculated and the results were plotted compared to correlation (1) for $\dot{m}=0.01 \mathrm{~kg} \cdot \mathrm{s}^{-1}$ and $q=300 \mathrm{~W} \cdot \mathrm{m}^{-2}$; see Figure 9. It is necessary to say that the previous simulations were carried out for boundary condition of constant foil temperature, while the data shown in Figure 9 represents the case of a constant heat flux density. However, in eq. (1) a constant $q$ approach is also considered. Thus, this simulation can only be used for an illustration why the calculated temperature in Figure 8 is slightly higher than the measured data. As Figure 9 shows, the only convection simulation case underestimates the heat transfer by about half compared to eq. (1). Hence in the real case more intensive cooling takes place. Values of Nusselt number were calculated using eq. (2) and (4). 


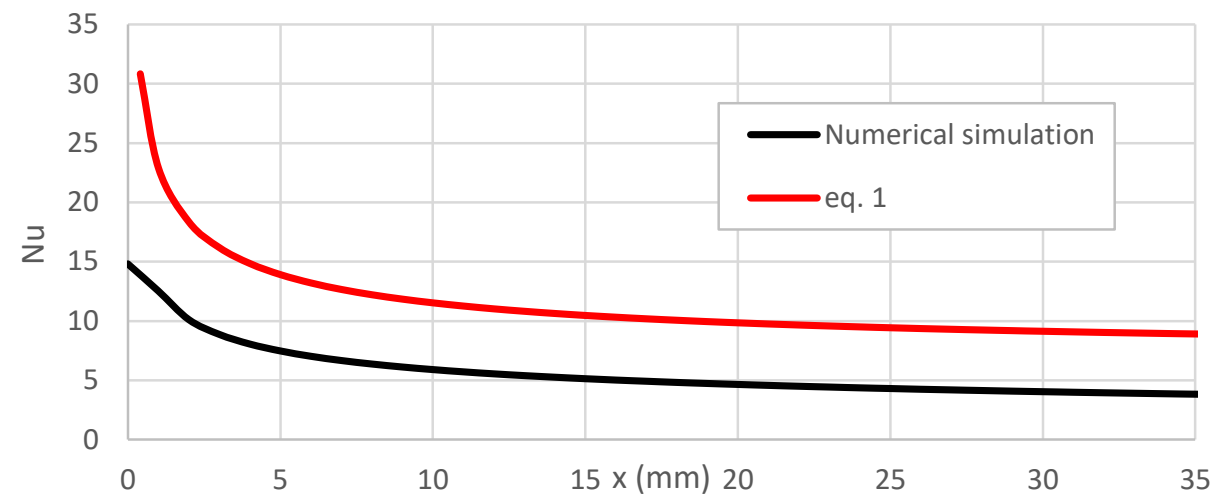

Fig. 9. Numerical data and eq. 1 comparison, $\dot{m}=0.01 \mathrm{~kg} \cdot \mathrm{s}^{-1}$ and $q=300 \mathrm{~W} \cdot \mathrm{m}^{-2}$, $T_{\text {in }}=21.1^{\circ} \mathrm{C}$.

\section{Conclusion}

A simplified 2D numerical simulation of a laminar non-isothermal flow with a heated wall was developed. The model was verified on the experimental data obtained in a testing glass channel. The simulated cases were solved with two different boundary condition when the temperature of the heating foil was set on the wall and a constant heat flux density was defined. The results obtained with the constant temperature lead to the good agreement of the temperature profile in the region before the transition. Then, in the region past the transition area the numerical results are overestimated, hence the temperature values are slightly higher. The relative deviation is less than $5 \%$ so the numerical model is validated as suitable for the future use. The requirement of the foil temperature as the input parameter for simulation have been found.

Since the temperature was measured by thermocouples which can disrupt the laminar water flow, some non-contact method, such as the thermal imaging, could be used. In addition, this method would provide continuous information about the surface temperature distribution at the bottom-wall not only in the $x$-axis.

The presented results will be used in further investigation of the thermal flow instabilities. The experience obtained within this study together with the validated numerical model will be used in the design of new experimental channel for investigation of a non-isothermal water flow.

\section{Nomenclature}

$\begin{array}{ll}A & \text { channel cross-section }\left(\mathrm{m}^{2}\right) \\ c_{\mathrm{p}} & \begin{array}{l}\text { specific isobaric thermal capacity } \\ \left(\mathrm{J} \cdot \mathrm{kg}^{-1} \cdot \mathrm{K}^{-1}\right)\end{array} \\ d & \text { wall thickness }(\mathrm{m}) \\ g & \text { gravitational acceleration }\left(\mathrm{m} \cdot \mathrm{s}^{-2}\right) \\ \mathrm{GzH} & \text { Graetz number, } H \mathrm{Re}_{\mathrm{H}} \mathrm{Pr} / x \\ h & \text { heat transfer coefficient } \\ & \left(\mathrm{W} \cdot \mathrm{m}^{-2} \cdot \mathrm{K}^{-1}\right) \\ H & \text { channel height }(\mathrm{m}) \\ k & \text { thermal conductivity } \\ & \left(\mathrm{W} \cdot \mathrm{m}^{-1} \cdot \mathrm{K}^{-1}\right) \\ L & \text { length }(\mathrm{m}) \\ \dot{m} & \text { mass flow rate }\left(\mathrm{kg} \cdot \mathrm{s}^{-1}\right)\end{array}$

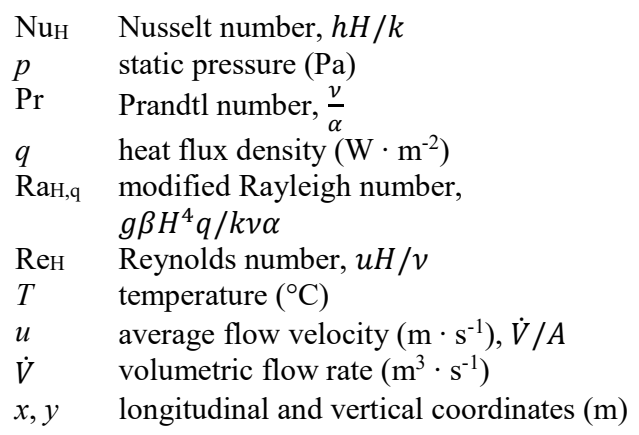



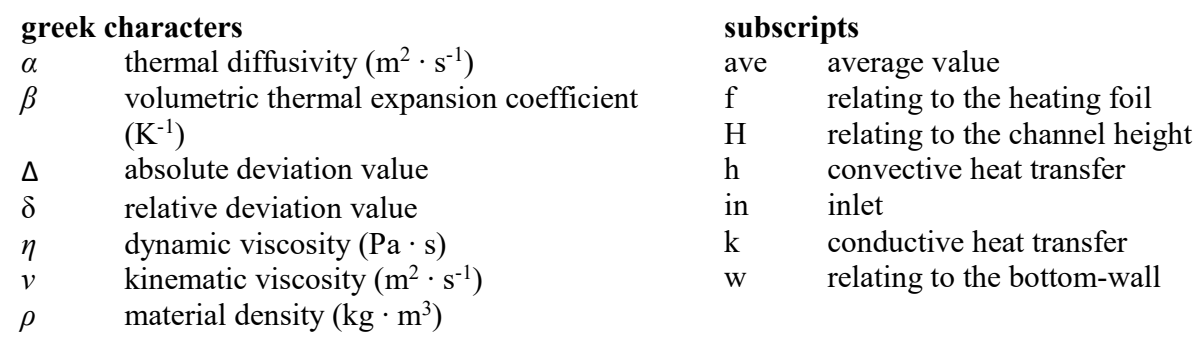

This work was supported by the Student Grant Competition of the Technical University of Liberec under the project No. SGS-2017-4006 and with the institutional support RVO: 61388998.

\section{References}

1. Osborne, Incropera, Laminar, mixed convection heat transfer for flow between horizontal parrallel plates with asymmetric heating. J. Heat and Mass Transfer., 28(1), 207-217, ISSN 0017-9310 (1985)

2. Incropera, Knox, Maughan, Mixed-Convection Flow and Heat Transfer in the Entry Region of a Horizontal Rectangular Duct. J. Heat Transfer., 109(2), 434-439, ISSN 1528-8943 (1987)

3. Maughan, Incropera, Secondary flow in horizontal channels heated from below. J. Experiments in Fluids., 5(5), 334-343, ISSN 0723-4864 (1987)

4. Benderradji, Haddan, Taher. Médale, Acid, Papini, Characterization of fluid flow patterns and heat transfer in horizontal channel mixed convection. J. Heat and Mass Transfer., 44(12), 1465-1476, ISSN 0017-9310 (2008)

5. Koffi, Abid, Medale, Papini, Mixed convection flow in a horizontal rectangular channel subjected to a horizontal thermal gradient. J. Heat and Mass Transfer. 2011, 47(10), 1251-1260, ISSN 0017-9310 (2011)

6. Mey, Westhoff, Wagner, Experimental Investigation of Flow Structure Formation in a Heated Duct Flow. In: Dillmann A., Heller G., Kreplin HP., Nitsche W., Peltzer I.: New Results in Numerical and Experimental Fluid Mechanics VIII. Notes on Numerical Fluid Mechanics and Multidisciplinary Design. Berlin: Springer (2013)

7. Luijkx, Platten, On the existence of thermoconvective rolls, transverse to a superimposed mean Poiseuille flow (1981)

8. Mergui, Nicolas, Hirata, Sidewall and thermal boundary condition effects on the evolution of longitudinal rolls in Rayleigh-Bénard-Poiseuille convection. J. Physics of Fluids., 23(8), ISSN 1089-7666 (2011)

9. Hwang, Liu, Convective Instability in the Thermal Entrance Region of a Horizontal Parallel Plate Channel Heated from Below. The Canadian Journal of Chemical Engineering., 54(6), 521-525, ISSN 1939-019X (1973)

10. Pulec, Dančová, Vinš, Survey of experimental channels employed on investigation of a non-isothermal laminar flow and design requirements for a new experiment. In: EFM (2019)

11. Maughan, Incropera, Regions of heat transfer enhancement for laminar mixed convection in a parallel plate channel. J. Heat and Mass Transfer., 33(3), 555-570, ISSN 0017-9310 (1990)

12. Lienhard, A Heat Transfer Textbook, 5th ed. (2020) 